\title{
MODERN NORMATIVITY AND THE POLITICS OF DEREGULATION
}

\author{
GEORCE A. TREY
}

Loyola University of Chicago

Juergen Habermas has recently made considerable strides in his understanding of the operations of late-capitalism and the types of political activities that are needed to transform the bureaucratic welfare state into a discursively mediated post-capitalist society. He attempts, nevertheless, to ground this program in normative standards that have developed coevally with the economic and political modes that he harshly criticizes: those of modernity. In the following paper I will argue that modern normativity is multi-dimensional, a feature ignored by Habermas that confounds the type of political agenda that he prescribes. In response I will suggest several reasons why a de-regulated form of politics is in order given his account of the late modern condition. I will also briefly highlight the main features of this model. 1

Habermas utilizes a theory of social evolution that demarcates three main phases: tribal, traditional and modern (TCA:2 156-172). The transition into the modern phase is characterized by decentralization of action orchestration through the development of both governmental and non-governmental subsystems. This is due partly to the emergence of a capitalist economy and the standardization of a monetary currency that serves as a medium of exchange between subsystems. The economy, as such, functions both as a medium of exchange between subsystems. The economy, as such, functions both as a subsystem and an interconnective substrata that coordinates relations within the subsystemic network. The state comes to rely on this coordinating mechanism which "forces it to reorganize and leads, among other things, to an assimilation of power to the structure of steering media: power becomes assimilated to muney" (TCA:2 171). Hence, political power and economical power become inseparable. On the positive side this frees action coordination from the confines of traditional norms, creating the condition for rational-discursive political legitimation. On the negative side, the efficiency mandates of the capitalist economy lead to a delinguistified mode of action coordination. Rather than discourse (as defined by Habermas), modernity is "steured" by the media money and power (TCA:2 171-172).

The prominence of steering media as coordinative devices weakens the capacity of the lifeworld to provide sucial integration. In Habermas' terms, the economic-political system is uncoupled from the

${ }^{1}$ A thorough discussion of this would require another paper featuring the work of Derrida and Foucault. 
lifeworld (the "horizon and backdrop of communicative action"-TCA:2 120): "The social system definitively bursts out of the horizon of the lifeworld, escapes from the intuitive knowledge of everyday communicative practice" (TCA:2 173). While structural differentiation within the lifeworld (duc to increased rationalization) delineates the domains appropriate to the three types of validity claims raised in conscnsual communication (those pertaining to truth, truthfulness and rightness) it likewise gives rise to increasingly complex systemic structures that tend to rope off or "colonize" the lifeworld. Consequently, the lifeworld becomes an ever shrinking subsystem, limiting its foundational role in action coordination. From the former aspect of rationalization emerges a system of abstract law and increased demand for consensual political legitimation; from the latter, a propensity for stecring media to infringe upon institutional domains (political, legal, etc.) that depend on highly developed communication structures (TCA:2 173-78). ${ }^{2}$

More recent developments in the capitalist economy (specifically the expansion of the welfare state) have intensified this problem. The "utopian energies" of modernity have decreased while steering media have become predominant. Habermas labels this "the new obscurity" which "is part of a situation in which the program of the social welfare state, which still feeds on the utopian energy of a laboring society, is losing its capacity to project future possibilities for a collectively better and less endangered way of life" (TNO 3-5).

Habcrmas proposes as a solution to this problem that existing political channels be bypassed as their communication structures are thoroughly distorted. The subsystemic media steered spheres must be transformed by autonomous collectivities that root themselves in what remainsd the lifeworld. Of existing means for social regulation-money, power and solidarity--solidarity needs to be positioned above the other two. This involves drawing upon the communicative capacity that is latent in the structures of the lifeworld. Habermas maintains that doing so will

2Habermas sceks to develop a theory of the lifeworld that avoids the subjective pitfalls of the phenomenological model developed by Shutz. and Luckmann. "Like Husserl, they begin with the egological consciousness for which the general structures of the lifeworld are given as necessary subjective conditions of the experience of a concretely shaped, historically stamped, social lifeworld" (TCA:2, page 129). The strength of this position is that the lifeworld is conceived as a socio-historically developed backdrop for action. The chief problem lies with the assumption that the acting subject is fundamental. In contrast, Habermas argues, the subject is always formed in contexts of intersubjectivity that are rooted in the communicative structures of the lifeworld. As such, the lifeworld serves as a pool of already given resources that can be thematized in validity claims. 
"influence the boundaries between communicatively structured areas of life, on the one hand, and the state and the economy, on the other", purportedly encouraging the development of communication oriented utopic visions of emancipation (TNO: 14-17).

While quite attractive on a purely theoretical level, even Habermas recognizes that there is little chance for this to serve as a viable practical solution to late modern crises or pathologies. "If I am not mistaken, the chances for this today are not very good. More or less in the entire Western world, a climate has developed that furthers capitalist modernization processes as well as trends critical of cultural modernism" (MP 13). In my estimation the problem lies in the very modern normativity that Habermas claims holds the solution to the aforementioned situation. His system/lifeworld distinction creates the illusion that the normative content of modernity is located exclusively in the lifeworld, making it the source pool from which progressive political activity must draw its energy. In contrast to this, I will argue that modern normativity is considerably more complex than Habermas acknowledges: that there are several levels of normativity that operate interdependently, preserving and transforming the systemic network that Habermas aptly describes. If my argument is correct, this situates the need for a different mode of political activism than that suggested by Habermas: one that is in a sense "deregulated". By relying on the questionable normative content of modernity Habermas (apparently by his own recognition) renders a complimentary practice implausible.

As I mentioned, for Habermas, the communicative structures of the lifeworld are the exclusive source of modern normativity. Modern lifeworld differentiations correspond to the components of speech-acts. The cultural sphere corresponds to propositional content; the societal sphere corresponds to illocutionary content; and the personal sphere corresponds to intentional content. Hence, the structures of language and the structures of the lifeworld are functionally interdependent. Construed as such, the lifeworld acts as a linguistic text: a source pool from which speech acts are thematized in specific contexts, providing the possibility for lucid communicative action coordination. The cultural sphere ensures semantic consistency with respect to objects in the world: so that when I say dog you envision a creature with four legs and a tail instead of one with wings and a beak. The societal sphere provides for continuity between spheres of action through mutual understanding: we can make the transition from one mode of collective activity to another. The personal sphere ensures that the concept of $I$ which is produced in contexts of we will endure and develop from generation to generation (PDM 342-345).

While Habermas is quick to point out that this is an idealization, that societies don't actually reproduce themselves in this manner, he does argue that formally, everything is in place to begin conducting social life on the basis of these lifeworld differentiations. Modernity is no longer 
strapped by mythologically legitimated knowledge; rather, what is constituted as knowledge hinges on consensus among appropriately empowered figures (such as a community of scientists). There is also greater lecway for personality development, enabling increased individuality. Finally, the idea of universal legal and moral structures has developed, providing formal protection against arbitrary changes based on power shifts. Habermas attributes this to the realization in lifeworld structures of the inherent qualities of language which correspond to the essential aspects of modern normativity: truth, freedom and justice.

Central to Habermas' argument is the claim that at no other time in the history of the West has there been so much potential for intersubjective communication. Truth, freedom and justice are defined in terms of democratic equality, therefore providing for a consensus oriented public sphere that is capable of producing in practice something similar to the "public will". "The procedures of discursive will formation established in the structurally differentiated lifeworld are set up to secure the social bond of all with all precisely through equal consideration of the interests of individuals" (PDM 346). Stating this in more linguistic terms: the system of personal pronouns that provides the referential basis of modern languages finds its home in the modern lifeworld; insofar as there is potential for direct interchange between "I" and "I" (ego and alter), the cstablishment of a well conceived "we", one that reflects the social, cconomic and political concerns of its referent, is possible. This also contributes to the process of secularization as the power of discourse overrides that of tradition.

While it is clear that modern theory moves in this direction, and that said theory is reflected in some constitutional discourses, it is questionable whether these discourses contribute to the establishment of consensus oriented polity or merely cloak the dominant modern practices that are justificd between the lines. Do the modern concepts of truth, frecdom and justice have conceptual foundations in democratic equality or in the stecring media of the modern mode of production-money and power (force)? If, as I will argue, the latter is the case, then the normative content of modernity is ambiguously related to programs of political action: that truth freedom and justice (which are worthy ideals) are normatively conceptualized in such a way that they certify the late-modern practices that Habermas carefully assesses and decries. As such, the type of political activity that is most appropriate to the circumstances described by Habermas must dismantle the convoluted normativity that has regulated modernity. In this sense, political action must be de-regulative.

It is important at this point to clarify what I mean by normative. I use this term, as does Habermas, to refer to the standards against which social, cconomic and political practices are measured. As such, it is crucial that an assessment of modern practices be factored into the evaluation of modern normativity. In Habermas' view, modern practices have deviated 
from the standards to which they are accountable. Human interchange is driven by economical imperatives that are coordinated through the steering media money and power. As a result, the system has overtaken almost every sphere of human life.

The deformation of a lifeworld that is regulated, fragmented, monitored, and looked after are surcly more subtle than the palpable forms of material exploitation and impoverishment; but internalized social conflicts that have shifted from the corporal to the psychic are not therefore less destructive. The legal-administrative means of translating social-welfare programs into actions are not some passive, as it were, propertyless medium. They are connected, rather, with a praxis that involves isolation of facts, normalization, and surveillance, the reifying and subjectivating violence of which Foucault has traced right down into the most delicate capillary tributaries of everyday communication" (PDM 362).

Clearly such practices are not in line with freedom, justice, and truth unless these concepts are defined relative to another set of imperatives.

The question that remains is whether this second set of imperatives deviates from or factors into modern normativity. Habermas himself raises this suspicion.

In the utopias painted in the old romances about the state, rational forms of life entered into a deceptive symbiosis with the technological mastery of nature and the ruthless mobilization of social labor power. This equation of happiness and emancipation with power and production has been a source of irritation for the selfunderstanding of modernity from the start-and it has called forth two centuries of criticism of modernity (PDM 366).

In spite of this, Habermas clings tightly to modern normativity; it is foundational to the directive principles that regulate his theory of socialpolitical action. In contrast, I will argue that later modern problems such as those mentioned above are indeed grounded in the complex, multidimensional normativity of the modern period. As such, the aforementioned "deceptive symbiosis" renders its normutive usefulness suspect. My criticisms will concentrate on the three normative principles, freedom, justice and truth, that play such an important role in Habermas' defense of modern normativity. 
Freedom is obviously not a concept that first appeared at the outset of the modern cpoch; it has a theoretical history that spans from Plato to Rawls. What distinguishes the modern version, according to Hahermas, is its universalistic conceptualization. Nevertheless, universal freedom hasn't been the norm. Further, some of the most significant forms of non-freedom--e.g. slavery, colonialism and imperialism-have bcen justificd on the basis of the formal concept of frecdom, with all its universalistic abstraction, that is native to modernity. Under a given interpretation of the constituted formulation, all such practices can be justified.

These of course are the obvious cases; ones that can in fact be accounted for as deviances. The more difficult cases are those alluded to above: ones using power strategies to permeate all spheres of human life for the sake of achieving and maintaining a distinctly modern form of productivity. This activity relies on institutions of pedagogy, mental health, manufacturing, administering and rehabilitation-all justified on the basis of humanistic values that repeatedly appeal to the concept of universal freedom considered to be fundamental to modernity. With Habermas, I would cite Foucault as the mater analyst of these practices. I question, however, his (Habermas') insistent claims that such practices are precluded by modern norms. Rather, I would argue, the norm of freedom has intermingled with, and been adjusted by the systemic norm of productivity. This is not to say that freedom isn't a modern norm in any sense. My point is that the modern concept of normative freedom is defined and institutionalized relative to the norm of production. As such, a political agenda that appeals to a clear and distinct modern concept of frecdom will be confounded by the fact that this concept has neither of these qualitics. This being the case, modern applications of the ideal of freedom must be challenged by action that seeks substantive freedom beyond the confines of the modern production paradigm.

As with freedom, justice was not first conceived during the modern period. It does, however, purportedly ascend to rationally determined standards of universality in its modern form. The feature of modern law that appeals to Habermas is its supposed applicability across the full range of individuals--recognizing no special cases or exceptions. When objectificd within a durable legal structure, these principles eliminate the contingencies of shifting regimes and arbitrary manipulations of law and order. The primary feature of this system is a stable center of political power--some form of republic--that can administer justice independent of the interests of particular administrators.

Clearly this ideal hasn't been met. The exploitation of child labor, sexual discrimination and unfair treatment due to race, gender and lifestyle preference in legal courts name just a few prevalent examples. These, however, as Habermas would be quick to point out, can be 
accounted for as practices in exception to, rather than legitimated by, the modern concept of justice. They are not conceptual problems but rather stem from residual biases that can be filtered out as we become mure "enlightened". 3

The harder cases are those that have prevailed during the latemodern period. Thuse fall into two categories. The first concerns sectors of society that regardless of legal reforms-both systemic and individual-are not dealt with justly. Included in this category would be the homcless, single parents, working women, ethnic minorities that are politically neutralized due to poverty and certain classes of elderly. Habermas associates the plight of these groups with the wclfare state in crisis: a function of incongruities that persist after legal adjustments have been made to provide for greater amounts of social and economic justice. There are no legal reasons why the aforementioned groups cannot achieve social, economic and political status equal to those from notably different situations. It is the very fact that formal legal justice is achieved that movement toward substantive justice is halted. My point is that these problems cannot be accounted for as deviations from modern standards of justice; rather, they are supported by a concept of justice that intermingles with a less prominent but more powerful modern principle. I will return to what this principle is after discussing the second category.

The second category concerns those aspects of the law which provide advantage to sectors of the population that possess a great deal of power. I would include in this tax laws that favor the affluent, criminal laws that almost encourage white collar crime and laws that allow for unsafe levels of contaminants to be put into the environment, as well as unsafe additives into food products. The fact that laws have been enacted to deal with these problems cloaks the abusive practices which ensue. My point once again is that the rhetoric of equality before the law is an accomplice of the principle which undergirds these practices.

The principle that 1 have in mind is profit. From the very beginning of the modern epoch an ethic of profit has been central: virtually any activity can find justification if it is profitable. When stated so bluntly this is of course offensive. Hence it is necessary to equate the

3 don't intend to trivialize these problems by claiming that they are merely exceptions to modern norms of justice. I consider them to be deeply rooted in the political economy of modernity. There are formal measures, however ineffective they may be, that "attempt" to address such situations. Therefore, it could be claimed that these are not systemically generated problems per se, but rather that they represent instances of abuse within a fundumentally correct system. If this is the case, then Habermas' modernist stance is not threatened by these cases as its critical force is the ability to unveil such exceptions. 
pursuit of profit with some principle of justice. This, I would argue, is the principle of justice that has developed in modernity. When pressure for legitimation becomes intensive, formally satisfying adjustments are made that have enough substance to quict unrest. They don't, however, lead to the kind of social change that is needed to eliminate the problem. When justice comes into conflict with the principle of profit, the powerful sectors of socicty that thrive on profit exercise their force to preserve favored position. Habermas could accept this argument on the basis of his analysis of modernity and respond that these are deviation from a more genuine sense of justice that is distinctly present in the modern lifeworld. My position is that this "genuine" level of justice is not as distinct as Habermas claims: that an analysis of late-modern practices reveals a conceptual interrelationship between the ideal of justice and the profit oriented imperatives of capitalism. Hence, an appeal to this concept of justice runs the risk of reinscribing the normative ambiguity that has brought about the current predicament.

The third component of modern normativity in Habermas' account is truth. Truth is primarily the product of science during the modern epoch and there is little doubt that science has flourished. The question, however, is whether it has been the quest for truth, or some other force, that has driven modern science. Once again, it is important to note that the modern sciences emerged at essentially the same time as the modern cconomy. As a result, the pursuit of truth has often been guided by production and profit in the form of technique. In the realm of the hard sciences, theoretical research is funded on the basis of potential for technical application, regardless of long range repercussions. This has brought us to the point where we are now dealing with the prospects of the greenhouse effect and mutually assured destruction. In the realm of the human sciences, technologies have been developed to shape subjects into uscful objects in the quest for production and profit. The truth of social scientific discourses is measured in terms of their application; if they do the job, they are true. Given this, it can be argued that the modern norm of truth intermingles with the imperative for developing technique: it is conceptualized relative to technical efficacy. I am not claiming that science doesn't produce anything true or that all modern science has been driven by technical motives. Nor am I claiming that scientists aren't motivated by the pursuit of truth. Rather, my point is that given the type of truth that feeds modern systems, the norm that guides scientific research is inseparable from technical imperatives. This being the case, a return to the origin of modern normativity will run the risk of merely reestablishing the modern form of truth production as the norm of truth cannot be cleanly distinguished from technical norms.

The arguments that I have presented are not incompatible with Habermas' assessment of modernity, nor his general theory that modern socicty has a bilevel (system/lifeworld) structure. They are, however, in 
opposition to his claim that the two levels of modern society are normatively distinguishable and that the lifeworld contains the last remaining kernels of unperverted modern normativity. My position is that the two levels of modern society both factor into modern normativity; and that the interplay between the two cloaks the operational motivation of numerous late-modern practices. If Habermas' view is accepted, a theory of social-political change must glance back to the pure normativity conceptualized early in the modern epoch. His appeal is to a modern rationality prior to its capitalistic corruption-reason that was originally a product of the lifeworld but which has been twisted into the service of system mandates. I have attempted to demonstrate that the two are inextricably intertwined and that remedial action should not yearn for the originary pristinity of enlightened (as opposed to corrupted) modernity.

Habermas' theory of social-political action requires a normative, or regulative principle. My position is that social-political action has to be deregulative. The scenario described by Habermas in his account of latemodern society suggests that illegitimate practices are the product of a complex web of relations that have developed into virtually impenetrable bureaucratic fortresses-literally taking on a life of their own. In order to change this situation, the structures that have developed need to be dismantled. For Habermas this involves a return to a normativity that he contends will serve as a wellspring of "utopian energy". I have argued that such a return runs the risk of being co-opted by the interplay that exists between lifeworld norms and system imperatives which function normatively. While Habermas' understanding of the linguistic-textual nature of both action coordination and progressive political activism is astute, his view that the linguistic operations of a social unit can be separated into categories of clear and distorted (present and non-present) communication is not supported by the account that he provides of latemodern practices. Therefore, I would advocate a form of social analysis that concentrates on the intermingling of clear and distorted linguistic operations. The attendant practice would operate within the cracks generated by this interplay. It is here-within these residual imprints--that de-regulated political strategies can begin to take shape. 4

Habermas' reason for retaining a normative format that he recognizes to be suspect is that it provides a safeguard against political nihilism. The type of political action that I am advocating, which is more deconstructive than reconstructive, he would claim does not. Habermas equates political strategies that are not principled on well conceived regulative standards with the anything goes ethos of fascism. This, I would

${ }^{4}$ For a more thorough discussion of this point see, George A. Trey. "The Philosophical Discourse of Modernity: Habermas' Post-Modern Adventure". diacritics (summer 1989): 67-89). 
contend, is a misconception-one that is arrested by a more rigorous analysis of political textuality. Such analyses, along with the practices they support, rely on critical principles that avoid the confinement and, as I have tricd to point out, the risks of universally instantiated norms. The fundamental difference between a critical principle and a norm is that the former is flexibly definite; it operates with conviction but is not rigid. Norms, on the other hand, lay claim to universality which translates into inflexibility. This is particularly problematic when established norms (such as those to which Habermas appeals) contain historically imbued clements which confound the achievement of the ideals that they represent. As such, critical principles, defined relative to seams in the political fabric which are vulnerable to penetrative activism, will facilitate the deployment of action strategies that are precluded by Habermas' abstract norms. Further, the risk of nihilism is offset by the checks and balances that the principles provide. Critical principles will by necessity incorporate values such as truth, freedom and justice. But, these values must be conceptualized relative to contexts of action rather than in terms of pre-established norms. Hence, the associated social-political agenda is not undermined by its own sense of propricty nor is it subject to the abusive sort of free play that Habermas envisions. 
Works Cited

Habermas, Juergen. The Theory of Communicative Action Vol. II. Thomas McCarthy Trans. Boston: Beacon Press, 1987.

-----The Philosophical Discourse of Modernity. Frederick Lawrence Trans. Cambridge: MIT Press, 1987.

- Modernity vs. Postmodernity". New Cerman Critique. Vol. 22 (1981) pp. 3-22.

-----"The New Obscurity: The Crisis of the Welfare State and the Exhaustion of Utopian Energies". Philosophy and Social Criticism. Vol. 11 (1986) pp. 1-17.

Key to Abbreviations

The Theory of Communicative Action Vol. II = TCA:2

The Philosophical Discourse of Modernity = PDM

"Modernity vs. Postmodernity" = MP

"The New Obscurity" = TNO 